\title{
Preparation and Characterization of Gelatin-polysaccharide Composite Hydrogels for Tissue Engineering
}

\author{
Jing Ye ${ }^{1}$, Gang Yang ${ }^{\text {Corresp., }}{ }^{1}$, Jing Zhang ${ }^{1}$, Zhenghua Xiao ${ }^{2}$, Ling He $^{1}$, Han Zhang ${ }^{1}$, Qi Liu ${ }^{1}$ \\ ${ }^{1}$ College of Biomedical Engineering, Sichuan University, Chengdu, Sichuan, China \\ 2 Department of Cardiovascular Surgery, West China Hospital of Sichuan University, Chengdu, Sichuan, China \\ Corresponding Author: Gang Yang \\ Email address: yang_gang@scu.edu.cn
}

Background: Tissue engineering, which involves the selection of scaffold materials, presents a new Background: Tissue engineering, which involves the selection of scaffold materials, presents a new therapeutic strategy for damaged tissues or organs. Scaffold design based on blends of proteins and polysaccharides, as mimicry of the native extracellular matrix, has recently become a valuable strategy for tissue engineering.

Objective: This study aimed to construct composite hydrogels based on natural polymers for tissue engineering. Methods: Composite hydrogels based on blends of gelatin with a polysaccharide component (chitosan or alginate) were produced and subsequently enzyme crosslinked. The other three hydrogels, chitosan hydrogel, sodium alginate hydrogel, and microbial transglutaminase-crosslinked gelatin (mTG/GA) hydrogel were also prepared. All hydrogels were evaluated for in vitro degradation property, swelling capacity, and mechanical property. Rat adipose-derived stromal stem cells (ADSCs) were isolated and seeded on (or embedded into) the above-mentioned hydrogels. The morphological features of ADSCs were observed and recorded. The effects of the hydrogels on ADSC survival and adhesion were investigated by immunofluorescence staining. Cell proliferation was tested by thiazolyl blue tetrazolium bromide (MTT) assay. Results: Cell viability assay results showed that the five hydrogels are not cytotoxic. The mTG/GA and its composite hydrogels showed higher compressive moduli than the single-component chitosan and alginate hydrogels. MTT assay results showed that ADSCs proliferated better on the composite hydrogels than on the chitosan and alginate hydrogels. Light microscope observation and cell cytoskeleton staining showed that hydrogel strength had obvious effects on cell growth and adhesion. The ADSCs seeded on chitosan and alginate hydrogels plunged into the hydrogels and could not stretch out due to the low strength of the hydrogel, whereas cells seeded on composite hydrogels with higher elastic modulus, could spread out, and grew in size. Conclusion: The gelatin-polysaccharide composite hydrogels could serve as attractive biomaterials for tissue engineering due to their easy 
preparation and favorable biophysical properties. 


\section{Preparation and Characterization of Gelatin-}

2 polysaccharide Composite Hydrogels for Tissue

3 Engineering

4

5

6

7

Jing Ye ${ }^{1}$, Gang Yang ${ }^{1 \#}$, Jing Zhang ${ }^{1}$, Zhenghua Xiao ${ }^{2}$, Ling He ${ }^{1}$, Han Zhang ${ }^{1}$, Qi Liu ${ }^{1}$

${ }^{1}$ College of Biomedical Engineering, Sichuan University, Chengdu, 610065, Sichuan, China

${ }^{2}$ Department of Cardiovascular Surgery, West China Hospital of Sichuan University, No.37 Guo Xue Alley, Chengdu 610041, China

\section{Corresponding Author:}

Gang Yang ${ }^{1}$

No.24 South Section 1, First Ring Road Chengdu, Sichuan, 610065, China

Email address: yang_gang@scu.edu.cn

\section{Abstract}

Background: Tissue engineering, which involves the selection of scaffold materials, presents a new therapeutic strategy for damaged tissues or organs. Scaffold design based on blends of proteins and polysaccharides, as mimicry of the native extracellular matrix, has recently become a valuable strategy for tissue engineering.

Objective: This study aimed to construct composite hydrogels based on natural polymers for tissue engineering.

Methods: Composite hydrogels based on blends of gelatin with a polysaccharide component (chitosan or alginate) were produced and subsequently enzyme crosslinked. The other three hydrogels, chitosan hydrogel, sodium alginate hydrogel, and microbial transglutaminase-crosslinked gelatin (mTG/GA) hydrogel were also prepared. All hydrogels were evaluated for in vitro degradation property, swelling capacity, and mechanical property. Rat adipose-derived stromal stem cells (ADSCs) were isolated and seeded on (or embedded into) the above-mentioned hydrogels. The morphological features of ADSCs were observed and recorded. The effects of the hydrogels on ADSC survival and adhesion were investigated by immunofluorescence staining. Cell proliferation was tested by thiazolyl blue tetrazolium bromide (MTT) assay. Results: Cell viability assay results showed that the five hydrogels are not cytotoxic. The mTG/GA and its composite hydrogels showed higher compressive moduli than the single-component chitosan and alginate hydrogels. MTT assay results showed that ADSCs proliferated better on the composite hydrogels than on the chitosan and alginate hydrogels. Light microscope observation and cell cytoskeleton staining showed that hydrogel strength had obvious effects on cell growth and adhesion. The ADSCs seeded on chitosan and alginate hydrogels plunged into the hydrogels and could not stretch out 
40

41

42

43

44

45

46

47

48

49

50

51

52

53

54

55

56

57

58

59

60

61

62

63

64

65

66

67

68

69

70

71

72

73

74

75

76

77

78

79

due to the low strength of the hydrogel, whereas cells seeded on composite hydrogels with higher elastic modulus, could spread out, and grew in size.

Conclusion: The gelatin-polysaccharide composite hydrogels could serve as attractive biomaterials for tissue engineering due to their easy preparation and favorable biophysical properties.

Keywords: composite hydrogel; gelatin; chitosan; alginate; tissue engineering

\section{Introduction}

Biomaterials for tissue engineering have been widely studied, and play a pivotal role in providing platforms that facilitate cell adhesion, growth, and proliferation. However, one of the major challenges in designing functional scaffolds is to modify their properties to mimic the extracellular matrix (ECM) in the native tissues. The composition of ECM includes structural proteins, adhesion proteins, anti-adhesion proteins, and proteoglycans. The natural biomaterials used for the engineering of tissue constructs show many obvious benefits for mimicking ECM, including collagen, gelatin (GA), hyaluronic acid, laminin, chitosan, and alginate (Schwach \& Passier 2019). Polysaccharides can increase the stability of scaffolds, whereas proteins can enhance the biological properties. Therefore, mixing protein components (such as GA) with polysaccharide components (such as chitosan and alginate) to form composite materials mimicking natural ECM has become an important strategy for tissue engineering applications (Afewerki et al. 2019).

GA as a degradation product of collagen has good biocompatibility, high hydration degree, and low market cost. Therefore, GA has become a well-known biological material. However, natural GA hydrogel has low mechanical stability, thereby severely limiting its application in tissue engineering. Several methods have been used to overcome its defects, including physical mixing, chemical crosslinking, and enzymatic crosslinking. Chemical crosslinking agents, such as glutaraldehyde and methacrylic anhydride, were used to crosslink the composite materials of GA and polysaccharides to obtain better mechanical properties (Majidi et al. 2018; Miranda et al. 2011; Rosellini et al. 2009). However, incomplete removal of chemical crosslinking agents may lead to cytotoxicity ( $\mathrm{Li}$ et al. 2009). Therefore, in our previous study, microbial transglutaminase (mTG) was used in place of chemical crosslinking agents to crosslink the composite materials, thereby resolving the problem of cytotoxic side effects (Yang et al. 2016).

Chitosan is a polysaccharide composed of glucosamine and $\mathrm{N}$-acetyl-glucosamine. It is obtained by removing some acetyl groups from chitin, and it also an analog of glycosaminoglycan, which is a component of ECM. Therefore, chitosan exhibits many interesting biological properties, including biocompatibility, hydrophilicity, antibacterial, and antithrombotic effects. Chenite et al. first reported that nearly neutral chitosan/ $\beta$-GP aqueous solutions could gel quickly when heated (Chenite et al. 2000). Thermosensitive chitosan hydrogel shows great potential in tissue engineering (Zhou et al. 2015). However, some authors reported that the thermosensitive chitosan hydrogel has insufficient mechanical strength when 
80

81

82

83

84

85

86

87

88

89

90

91

92

93

94

95

96

97

98

99

100

101

102

103

104

105

106

107

108

109

110

111

112

113

114

115

116

117

118

119

used as a tissue engineering material (Sacco et al. 2018; Supper et al. 2014; Zhang et al. 2019). Huang and coworkers constructed composite scaffolds comprising a chitosan hydrogel system and demineralized bone matrix, which exhibited an increased mechanical strength; the bone marrow stem cell (BMSC) retention of the hybrid scaffolds was more efficient and uniform than that of the other materials (Huang et al. 2014). Song et al. reported that ADSCs within the chitosan/ $\beta$-GP/collagen hydrogels displayed a typical adherent cell morphology and good proliferation with very high cellular viability after 7 days of culture (Song et al. 2010). These experimental results indicated the possibility of overcoming the defects of chitosan gel by mixing with other materials, and composite scaffolds based on chitosan may be promising candidates for tissue engineering.

Alginate is a natural polysaccharide isolated from brown algae and bacteria. It has good biocompatibility and non-antigenicity; it is also antithrombotic and biodegradable. Besides, alginate has the advantages of having abundant sources and being low cost. Among the strategies used for the obtention of alginate hydrogel, the most widespread is ionic crosslinking (Sun \& Tan 2013). In the presence of multivalent cations, crosslinking is instantaneous and almost temperature-independent and allows solution/gel transformation under relatively mild conditions (Cattelan et al. 2020). Alginate hydrogel has been widely used in tissue engineering and has been approved for phase II clinical trials in the treatment of MI (Lee \& Mooney 2012). However, alginate hydrogel has natural poor cell adhesion and poor in vivo degradation performance (Bedian et al. 2017; Tønnesen \& Karlsen 2002). To solve these problems, mixing alginate with natural proteins, such as collagen, fibronectin, and GA, has been proposed (Hernández-González et al. 2020). Complexes of alginate and GA are interesting to use in tissue engineering, because they can provide suitable biological cues for hosting a variety of cells, including $\mathrm{C} 2 \mathrm{C} 12$ myoblasts (Rosellini et al. 2018), HL1 cardiac muscle cell (Xu et al. 2009), neonatal rat ventricular myocytes (NRVMs) (Möller et al. 2011), and fetal rat myoblast H9C2 (Saberianpour et al. 2019).

Composite methods of GA and polysaccharides have been proposed, and the materials obtained through such methods support cell adhesion, proliferation, and differentiation (Miranda et al. 2011; Rosellini et al. 2009; Rosellini et al. 2018). Generally, strategies for preparing composite hydrogels include physical mixing (Liu et al. 2013), crosslinking (Rosellini et al. 2019), in situ synthesis (Wang et al. 2009), bio-conjugation (Ahadian et al. 2015), and others. In our composite hydrogels, enzymatic modification of proteins mediated by $\mathrm{mTG}$ is applied and aims to improve the properties of target products. These enzymatic reactions occur under mild reaction conditions and do not produce toxic products (Fatima \& Khare 2018). Marcelo et al. proved the feasibility of using mTG as a crosslinking agent for chitosan and GA hydrogel (da Silva et al. 2014). Moreover, the microstructure of alginate GA-hydrogel microspheres was confirmed to be affected by GA content and mTG concentration (Pilipenko et al. 2019).

Adipose-derived stromal stem cells (ADSCs) are adult stem cells with abundant cell sources and provide a potential source of stem cells for tissue engineering research and clinical application (Suzuki et al. 2015). In this study, the preparation of chitosan/mTG-crosslinked GA 
120 (C-mTG/GA) and alginate/mTG-crosslinked GA (A-mTG/GA) was proposed, which are two 121 kinds of composite hydrogels. Swelling, enzymatic degradation, and mechanical tests were

122

123

124

125

126

127

128

129

130

131

132

133

134

135

136

137

138

139

140

141

142

143

144

145

146

147

148

149

150

151

152

153

154

155

156

157

158

performed. Viability and proliferation tests of ADSCs seeded on the composite hydrogels were conducted to determine the applicability of the hydrogels in tissue engineering. Finally, the cytoskeleton features of the ADSCs' distribution on hydrogels were evaluated (Fig.1B).

\section{Materials \& Methods}

\section{Materials}

Microbe transglutaminase (mTG, Bomei, China; enzyme activity, $>100$ U per gram), highglucose Dulbecco's modified Eagle's medium (DMEM, Hyclone, UT, USA), fetal bovine serum (FBS, Gibco, NY, USA), and penicillin/streptomycin (P/S; Hyclone, UT, USA) were used.

Trypsin (250 NFU/mg), ethylene diamine tetraacetic acid (EDTA), and collagenase type I ( $>125$ $\mathrm{NFU} / \mathrm{mg}$ ) were purchased from Invitrogen (CA, USA). GA (type A, 300 Bloom), beta-sodium glycerophosphate ( $\beta$-GP), calcein-AM, propidium iodide (PI), thiazolyl blue tetrazolium bromide (MTT), dimethyl sulfoxide (DMSO), aqueous formaldehyde, Triton X-100, 4,6-diamidino-2phenylindole (DAPI), and fluorescein isothiocyanate (FITC)-phalloidin were purchased from Sigma (MO, USA). Chitosan (molecular weight: $100-300 \mathrm{kDa}$, degree of deacetylation: $\geq 85 \%$ ), sodium alginate $(\mathrm{Mw}=220,000$ and $\mathrm{M} / \mathrm{G}$ ratio $=0.38)$, calcium chloride $\left(\mathrm{CaCl}_{2}\right)$, sodium chloride $(\mathrm{NaCl})$, and acetic acid were purchased from Kelong (Chengdu, China). Analytical- or chemical-grade reagents were used.

\section{Preparation of hydrogels Preparation of chitosan hydrogel}

Preparation of chitosan hydrogel was performed according to the method described elsewhere (Chenite et al. 2000) with minor modifications. Chitosan was placed on a piece of weighing paper, spread out, and exposed to ultraviolet (UV) light for $45 \mathrm{~min}$, during which it was slightly turned over 3 times. The UV-disinfected chitosan particles were transferred to a sterile clean bench and dissolved in $0.1 \mathrm{M}$ acetic acid. After stirring with a glass rod, it was placed at $4{ }^{\circ} \mathrm{C}$ for $24 \mathrm{~h}$ and centrifuged at $8000 \mathrm{rpm}$ for $10 \mathrm{~min}$. The supernatant was collected to obtain the final chitosan solution concentration of $2 \%(\mathrm{w} / \mathrm{v}$, weight volume ratio). This solution was stored at $4{ }^{\circ} \mathrm{C}$. $\beta$-GP was dissolved in deionized water to obtain $50 \%$ (wt, weight ratio) solution, sterilized and passed through a $0.22 \mu \mathrm{m}$ filter, and stored at $4{ }^{\circ} \mathrm{C}$. During the preparation of the chitosan hydrogel, the $\beta$-GP solution was slowly dripped into the chitosan solution on the ice bag. The ratio of chitosan solution to $\beta$-GP solution was 5:1 (Qiu et al. 2010), and the $\mathrm{pH}$ value was adjusted to 7.4 . The mixed solution at $200 \mu \mathrm{L}$ was added into a 24 -well tissue culture plate (TCP) and placed into each well. The solution was incubated at $37^{\circ} \mathrm{C}$ for $10 \mathrm{~min}$ to obtain chitosan hydrogel (Fig.1A).

\section{Preparation of alginate hydrogel}


159

160

161

162

163

164

165

166

167

168

169

170

171

172

173

174

175

176

177

178

179

180

181

182

183

184

185

186

187

188

189

190

191

192

193

194

195

196

197

198

199

After disinfection by UV (as conducted in Section 2.2.1), sodium alginate was dissolved in sterilized phosphate buffered saline (PBS) solution to form $1 \%(\mathrm{w} / \mathrm{v})$ solution. $\mathrm{CaCl}_{2}$ and $\mathrm{NaCl}$ were mixed with deionized water to form solutions at final concentrations of 100 and $150 \mathrm{mM}$, respectively. After high-pressure steam sterilization, $\mathrm{CaCl}_{2} / \mathrm{NaCl}$ solution was stored at $4{ }^{\circ} \mathrm{C}$. To prepare the alginate hydrogel, the sodium alginate solution was placed into a 24-well TCP (200 $\mu \mathrm{L}$ placed in each well). Then, $1 \mathrm{~mL}$ of $\mathrm{CaCl}_{2} / \mathrm{NaCl}$ solution was slowly dropped into each well. After soaking for $10 \mathrm{~min}$ at room temperature, the excess liquid was removed, and sodium alginate hydrogel was obtained (Fig.1A).

\section{Preparation of $\mathrm{mTG} / \mathrm{GA}$ hydrogel}

$\mathrm{mTG} / \mathrm{GA}$ hydrogel was prepared using a protocol described in our previous publication (Long et al. 2017; Yang et al. 2016). GA was dissolved in PBS at $50{ }^{\circ} \mathrm{C}$ to obtain a solution, which was sterilized and passed through a $0.22 \mu \mathrm{m}$ filter. mTG was dissolved in PBS to prepare $10 \%$ (wt) solution, which was sterilized and passed through a $0.22 \mu \mathrm{m}$ filter. mTG/GA solution was prepared by adding mTG into the GA solution at $10 \mathrm{U} / \mathrm{g} \cdot$ pro (enzymatic activity unit per gram of protein). Then, the mixed solution with a final GA concentration of $6 \%(\mathrm{w} / \mathrm{v})$ was added into a 24-well TCP; $200 \mu \mathrm{L}$ of the solution was placed into each well. The sample was incubated at $37^{\circ} \mathrm{C}$ for $30 \mathrm{~min}$ for gelling (Fig.1A).

\section{Preparation of C-mTG/GA and A-mTG/GA hydrogels}

$\mathrm{mTG} / \mathrm{GA}$, chitosan, and sodium alginate solutions were prepared as mentioned above. The $7.5 \%(\mathrm{w} / \mathrm{v}) \mathrm{GA}$ with $10 \mathrm{U} / \mathrm{g} \cdot$ pro $\mathrm{mTG}$ and $2 \%(\mathrm{w} / \mathrm{v})$ chitosan (or $1 \%(\mathrm{w} / \mathrm{v})$ sodium alginate) solutions were mixed in a volume ratio of $4: 1$. The composite process was conducted on a hot platform (DB-H, Xinbao, China) at $37{ }^{\circ} \mathrm{C}$. The mixtures with a final GA concentration of $6 \%$ (w/v) were added into 24 -well TCPs; $200 \mu \mathrm{L}$ of the mixtures was placed into each well. The solutions were incubated at $37^{\circ} \mathrm{C}$ for $20 \mathrm{~min}$ to obtain $\mathrm{C}-\mathrm{mTG} / \mathrm{GA}$ and A-mTG/GA hydrogels (Fig.1A).

\section{Characterization of hydrogels Gelation time}

Ungelled mTG/GA mixture, $\beta$-GP/chitosan, $\mathrm{C}-\mathrm{mTG} / \mathrm{GA}$, and A-mTG/GA solutions ( $1 \mathrm{~mL}$ ) were added into $2 \mathrm{~mL}$ microtubes and incubated at $37^{\circ} \mathrm{C}$ for gel. Sodium alginate solution at 1 $\mathrm{mL}$ was added into a $2 \mathrm{~mL}$ microtube, and $\mathrm{CaCl}_{2} / \mathrm{NaCl}$ solution was dropped for gelling. The onset of gelling was recorded as the gelation time, which was detected through the vial inverting method.

\section{Hydrogel degradation test}

In vitro enzymatic degradation property: The in vitro enzymatic degradation property of hydrogels was evaluated by exposing them to enzymes to assess degradation rate. Collagenase has been used previously as a mimic for some of the protease secreted by cells (Mazzeo et al. 2019), and trypsin is often used in cell isolation and culture. The material degradation process of these proteases must be evaluated to provide a basis for cellular inoculation and digestion on hydrogels. The pre-weighed hydrogels $\left(w_{0}\right)$ were then immersed in $0.1 \%$ collagenase type I and $0.25 \%$ trypsin $/ 0.01 \%$ EDTA for $12 \mathrm{~h}$. At each time point $(0.25,0.5,1,2,3,4,5,6,7,8,9,10$, 
20011 , and $12 \mathrm{~h}$ ), the liquid was removed completely. The hydrogels were weighed again $\left(w_{t}\right)$. The 201 degree of degradation (D) was calculated as follows:

202

203

204

205

206

207

208

209

210

211

212

213

214

215

216

217

218

219

220

221

222

223

224

225

226

227

228

229

230

231

232

233

234

235

236

237

238

239

$$
\mathrm{D}(\%)=\left(w_{0}-w_{t}\right) / w_{0} \times 100 .
$$

Three repeated measurements were performed for each type of hydrogel.

Hydrolytic and cellular degradation: The hydrolytic and cellular degradation of hydrogels were performed as described by our previous study(Yang et al. 2016). In brief, hydrogels were prepared into $35 \mathrm{~mm}$ culture dishes with $\sim 1 \mathrm{~mL}$ for each dish. To exclude the influence of swelling behavior of hydrogels, $2 \mathrm{~mL}$ of PBS was added into each dish and PBS was removed completely after $12 \mathrm{~h}$; the hydrogels were weighed $\left(w_{0}\right)$. The hydrogels were incubated in PBS at $37{ }^{\circ} \mathrm{C}$ with $5 \% \mathrm{CO}_{2}$ for two weeks. PBS was changed every 2 days. At different time points $(0,2,4,6,8,10,12$, and $14 \mathrm{~d})$, three samples of each kind of hydrogel were weighed $\left(w_{t}\right)$. the degree of degradation was calculated as above. Cell-mediated degradation was measured by seeding $1.0 \times 10^{6} \mathrm{ADSCs}$ (see 'Primary culture of ADSCs') on each hydrogel scaffold. The rest of the steps were the same as above, except that the PBS was changed to cell culture medium (high-glucose DMEM, 15\% FBS, and 1\% P/S).

\section{Swelling capacity}

Each type of hydrogel was prepared and weighed $\left(w_{1}\right)$. The hydrogels were immersed into PBS for $12 \mathrm{~h}$ at $37^{\circ} \mathrm{C}$, and excess PBS was blotted out with filter paper. The swollen hydrogels were obtained and re-weighed $\left(w_{2}\right)$. Swelling ratio $(\mathrm{S})$ was calculated as follows:

$$
\mathrm{S}(\%)=\left(w_{2}-w_{1}\right) / w_{1} \times 100 .
$$

Three repeated measurements were performed for each type of hydrogel.

\section{Mechanical property}

The mechanical property of the hydrogels was evaluated using a mechanical testing apparatus (HPB, Handpi, China). The effects of sample cutting were considered. Only the samples with the same dimensions were selected as test specimens. For this purpose, cylindershaped samples were cut to achieve a diameter of $15 \mathrm{~mm}$ and a thickness of $6 \mathrm{~mm}$. The sample was fixed on a hot platform and examined at $37^{\circ} \mathrm{C}$. The detecting probe was a stainless steel cylinder (12.5 $\mathrm{mm}$ in diameter) with a flat front attached to the mechanical testing machine. The hydrogels were compressed at a constant deformation rate of $1.0 \mathrm{~mm} / \mathrm{s}$. Meanwhile, the value of loading force was recorded automatically by using a mechanical testing software (Handpi, China). The slopes of compressive stress-strain curves at $0 \%$ to $50 \%$ deformation were used to calculate the compressive modulus. The reported values are the mean of six specimens.

\section{Primary culture of ADSCs}

The study protocol was approved by the Institutional Animal Care and Use Committee of Sichuan University (approval number: KS2019006). ADSCs were isolated as described previously (Yang et al. 2016). Subcutaneous adipose tissue was obtained from a SpragueDawley rat (weighed $100 \mathrm{~g}$, either male or female) and finely minced. The minced tissue was placed in a digestion solution containing $0.1 \%$ collagenase type I and subjected to continuous agitation at $37^{\circ} \mathrm{C}$ for $45 \mathrm{~min}$. The cell suspension was filtered and centrifuged at $2000 \mathrm{rpm}$ for 5 
240

241

242

243

244

245

246

247

248

249

250

251

252

253

254

255

256

257

258

259

260

261

262

263

264

265

266

267

268

269

270

271

272

273

274

275

276

277

278

279

min. Cellular precipitation was resuspended with the cell culture medium and cultured in $25 \mathrm{~mm}^{2}$ cell flasks. The cells were cultured at $37^{\circ} \mathrm{C}$ in a $5 \% \mathrm{CO}_{2}$ incubator, and the medium was changed twice a week. Cultures were passaged every 5 days. The cells were observed daily under an inverted phase-contrast microscope (CKX41, Olympus, JAPAN). The cells were detached with $0.25 \%$ trypsin/0.01\% EDTA and re-plated for cell passage. The third-passage ADSCs were used for the subsequent experiments.

\section{Cell viability}

2D culture: Different types of hydrogels were prepared as described above. After washing with PBS, the hydrogels were ready for cell culture. ADSCs were seeded on the surface of the hydrogels at $1.0 \times 10^{4}$ cells per well. ADSCs at same number were seeded on non-hydrogel TCPs as controls.

3D culture: ADSCs were prepared as described above and cell density was adjusted to 5.0 $\times 10^{6}$ cells $/ \mathrm{ml}$. The cell/hydrogel mixtures were obtained by mixing cell suspensions and different hydrogel solutions at 1:9 volume ratio and the mixtures were pipetted into the wells of a 24 -well culture plate at $100 \mu \mathrm{L}$ per well $\left(\sim 5.0 \times 10^{4}\right.$ cells per well). The cell/hydrogel constructs were incubated at $37^{\circ} \mathrm{C}$ for $2 \mathrm{~h}$ and then supplemented with cell culture medium.

On day 5 of ADSC culture, the cell-cultured samples were washed thrice with PBS and incubated in $250 \mu \mathrm{L}$ PBS containing $2 \mu \mathrm{M}$ calcein-AM and $2 \mu \mathrm{M}$ PI at $37^{\circ} \mathrm{C}$ for $30 \mathrm{~min}$. After re-washing with PBS, the cells were observed by using an inverted fluorescent microscope (XDS30; Sunny Instruments, China) equipped with a color digital camera (MD50; Mingmei, China). The viability of ADSCs was determined by staining with calcein-AM and with PI to label the live and dead cells, respectively.

\section{Cell proliferation studies}

ADSCs were seeded on the hydrogels and TCPs as described above at $1 \times 10^{4}$ cells per well. Cell proliferation was determined by MTT assay on days $0,2,4$, and 6 of cell culture. At each time interval, the cell-cultured samples (three replicates) were rinsed thrice with PBS and treated with $800 \mu \mathrm{L}$ of high-glucose DMEM containing $80 \mu \mathrm{L}$ of MTT solution $(5 \mathrm{mg} / \mathrm{mL}$ in PBS) at $37^{\circ} \mathrm{C}$ for $4 \mathrm{~h}$. The supernatant was removed after incubation, and the formazan crystals in the cells were dissolved in $400 \mu \mathrm{L}$ of DMSO. Then, the absorbance of $100 \mu \mathrm{L}$ of supernatant transferred to a new 96-well TCP was measured at $490 \mathrm{~nm}$ with a reference wavelength of 630 $\mathrm{nm}$ by using a microplate reader (Biotek ELx800, USA). Background absorbance from the control wells, which contained the culture medium but without cells, was subtracted.

\section{Cytoskeleton staining}

Cells were seeded on the hydrogels and TCPs at $1 \times 10^{5}$ cells per well (6-well TCPs) and cultured for 5 days. Cells were fixed with $4 \%(\mathrm{w} / \mathrm{v})$ aqueous formaldehyde solution for $15 \mathrm{~min}$ at room temperature, and permeabilized with $0.1 \%(\mathrm{v} / \mathrm{v})$ Triton X-100 solution in PBS for $10 \mathrm{~min}$. Afterward, they were stained with $5 \mu \mathrm{g} / \mathrm{mL}$ FITC- for $30 \mathrm{~min}$ followed by $1 \mu \mathrm{g} / \mathrm{mL}$ DAPI for 10 
280

281

282

283

284

285

286

287

288

289

290

291

292

293

294

295

296

297

298

299

300

301

302

303

304

305

306

307

308

309

310

311

312

313

314

315

316

317

318

319

min. After incubation, fluorescent images were acquired using the inverted fluorescent microscope equipped with a digital camera.

\section{Statistical analysis}

Statistical analyses were performed using SPSS software (SPSS Inc.). Each experiment was repeated $\geq 3$ times. Data are presented as mean with standard deviation. Statistical significance between two groups was determined by an independent sample Student's t-test. The level of statistical significance was $\mathrm{P}<0.05$.

\section{Results}

\section{Characterization of hydrogels}

\section{Gelation time and appearance of hydrogels}

The chitosan samples at $1 \mathrm{~mL}$ of $2 \%(\mathrm{w} / \mathrm{v})$ gelatinized after the addition of $\beta$-GP solution within $10 \mathrm{~min}$ at $37^{\circ} \mathrm{C}$, and the obtained hydrogel was opaque and light yellow. The GA samples at $1 \mathrm{~mL}$ of $6 \%(\mathrm{w} / \mathrm{v})$ needed approximately $30 \mathrm{~min}$ to achieve gelling at $37^{\circ} \mathrm{C}$. The $\mathrm{mTG} / \mathrm{GA}$ hydrogel was colorless and transparent. This result was consistent with that obtained in our previous study (Yang et al. 2016), in which we reported that the $6 \%$ solution of GA mixed with mTG took $25 \pm 0.55 \mathrm{~min}$ to gel. Alginate hydrogel samples at $1 \mathrm{~mL}$ of $1 \%(\mathrm{w} / \mathrm{v})$ were obtained by $\mathrm{Ca}^{2+}$-crosslinking at room temperature within $10 \mathrm{~min}$. When the calcium solution was dropped into the alginate solution, the edge started to shrink immediately and form wrinkles. After removing the additional liquid, we obtained a translucent white alginate hydrogel with uneven thickness. Samples of the two composite solutions $(1 \mathrm{~mL})$ prepared as mentioned in Section 2.2.4 gelatinized within $20 \mathrm{~min}$ at $37^{\circ} \mathrm{C}$. The $\mathrm{C}-\mathrm{mTG} / \mathrm{GA}$ hydrogel was translucent yellow. The A-mTG/GA hydrogel was colorless and transparent (Fig. 1C-G).

Figure 1. Schematic elucidating the preparation and characterization of the five hydrogels. A. Schematic showing the five hydrogels fabrication process. (1) Preparation of chitosan hydrogel. (2) Preparation of alginate hydrogel. (3) Preparation of mTG/GA hydrogel. (4) Preparation of two composite hydrogels. B. Characterization and biological assessments of the five hydrogels. C-G. The appearance of the five tested hydrogels. Scale bar $=1 \mathrm{~cm}$.

\section{Swelling capacity}

Swelling capacity reflects the hydrophilic character and water retention capacity of hydrogels, and is also an important factor for predicting nutrient transfer within hydrogels (Gu et al. 2020). After being immersed in PBS for $24 \mathrm{~h}, \mathrm{mTG} / \mathrm{GA}, \mathrm{C}-\mathrm{mTG} / \mathrm{GA}$, and A-mTG/GA hydrogels were slightly expanded, whereas the volumes of chitosan and alginates hydrogels almost remained unchanged. Swelling ability is an important index for hydrogels that are used in tissue engineering. We evaluated the swelling rate of the five hydrogels (Table 1). Chitosan and 
320

321

322

323

324

325

326

327

328

329

330

331

332

333

334

335

336

337

338

339

340

341

342

343

344

345

346

347

348

349

350

351

352

353

354

355

356

357

358

359

alginate hydrogels showed maximum swelling rates of $1.55 \pm 0.89 \%$ and $4.68 \pm 0.87 \%$, respectively, in PBS. Both swelling rates were significantly lower than that of the other three hydrogels. The swelling rate of mTG/GA hydrogel was $21.33 \pm 3.56 \%$. Although with the same concentration of GA, the swelling rate of C-mTG/GA hydrogel decreased to $14.29 \pm 2.28 \%$ (P< $0.05)$. The swelling rate of A-mTG/GA hydrogel $(20.72 \pm 0.84 \%)$ did not differ significantly from that of mTG/GA hydrogel $(21.33 \pm 1.78 \%, \mathrm{P}=0.62>0.05)$.

Table 1. Gelation time, swelling rate and compression modulus of the five tested hydrogels.

$$
* \# \wedge \mathrm{P}<0.05
$$

\section{Mechanical property}

As cardiac tissue engineering substrates, the hydrogels need to have proper mechanical properties. We used a mechanical testing machine to evaluate the compression modulus (Table 1). Chitosan and alginate hydrogels exhibited low compression moduli (3.48 \pm 0.9 and $7.06 \pm$ $2.44 \mathrm{kPa})$. Compared with mTG/GA hydrogel $(17.42 \pm 2.68 \mathrm{kPa})$, the strength of the composite hydrogel showed a decreasing trend after mixing with chitosan $(14.29 \pm 5.28 \mathrm{kPa}, \mathrm{P}<0.05)$, whereas the strength of the composite hydrogel showed an increased trend after mixing with sodium alginate $(19.79 \pm 2.44 \mathrm{kPa}, \mathrm{P}<0.05)$. These results may be related to the formation of intermolecular interactions (electrostatic interaction and hydrogen bonding) between the polypeptide chains of GA and the macromolecules of polysaccharides. The additional junctions in the complex gel network result in changes in elasticity compared with those of native GA (Derkach et al. 2020).

\section{Hydrogel degradation test}

Cells can produce different proteolytic enzymes via autocrine and/or paracrine, which may lead to the degradation of hydrogel. Therefore, the in vitro enzymatic degradation of hydrogels should be evaluated. Degradation tests in two parallel groups were conducted, namely, collagenase and trypsin degradation groups. The curves of enzymatic degradation are shown in Fig. 2. In the collagenase degradation tests, the C-mTG/GA hydrogel showed the fastest degradation rate, in which more than $30 \%$ of the original weight was lost in $15 \mathrm{~min}$, and only $0.20 \pm 0.36 \%$ remained after $5 \mathrm{~h}$. During degradation by collagenases, mTG/GA and A-mTG/GA hydrogels also showed obvious degradation. Complete degradation of mTG/GA hydrogels occurred within $6 \mathrm{~h}$, and complete degradation of A-mTG/GA hydrogels required $7 \mathrm{~h}$. However, the enzymolysis rates of chitosan and alginate hydrogels were markedly slower than those of the other three hydrogels. For alginate hydrogel, only $13.76 \pm 3.57 \%$ of the hydrogel was lost after $12 \mathrm{~h}$. For chitosan hydrogel, approximately $96 \%$ remaining after digestion for $12 \mathrm{~h}$.

Based on the trypsin degradation tests, mTG/GA and C-mTG/GA hydrogels almost completely dissolved after $2 \mathrm{~h}$ of enzymatic degradation. A-mTG/GA hydrogels showed slower degradation rate and were degraded completely by trypsin within $8 \mathrm{~h}$. Alginate hydrogels showed 
360

361

362

363

364

365

366

367

368

369

370

371

372

373

374

375

376

377

378

379

380

381

382

383

384

385

386

387

388

389

390

391

392

393

394

395

396

397

398

399

400

nearly half of the mass loss after $12 \mathrm{~h}$. However, chitosan hydrogel did not show degradation after $1 \mathrm{~h}$, and its final mass after $12 \mathrm{~h}$ remained at approximately $90 \%$.

All hydrogels exhibited high capacity for hydrolytic resistance. After two weeks of immersion, all of the five kinds of hydrogels retained more than $95 \%$ of their original mass. In the test of cell-containing hydrogels, we found that all hydrogels degraded more rapidly than cell-free hydrogels. For two weeks, $25.1 \pm 3.48 \%$ of $\mathrm{mTG} / \mathrm{GA}$ hydrogel mass was lost. Moreover, the alginate hydrogel also showed significant degradation. At the second week, $12.2 \pm$ $2.99 \%$ of the hydrogel mass was lost. However, the mTG/GA, C-mTG/GA, and A-mTG/GA hydrogels did not show severe degradation. For C-mTG/GA, and A-mTG/GA hydrogels, approximately $5 \%$ of gel mass was lost after two weeks of incubation; meanwhile for chitosan hydrogel, mass loss was $1.2 \pm 0.58 \%$. These results may suggest that the incorporation of polysaccharides can help strengthen cellular degradation resistant capacity of GA-containing hydrogels.

Figure 2. In vitro degradation property of the five hydrogels. A. The curves of $0.1 \%$ collagenase degradation. B. The curves of $0.25 \%$ trypsin $/ 0.01 \%$ EDTA degradation. C. The curves of hydrolysis degradation. D. The curves of cellular degradation.

\section{Cell morphological observation}

To observe the growth and adhesion of ADSCs on hydrogel surface and verify the biocompatibility of the hydrogels, cell images were recorded by using the inverted phase contrast microscope. Fig. 3 shows the cell morphology of $2 \mathrm{D}$ cultures on the five hydrogels for $2 \mathrm{~h}, 1$ day, and 3 days. After inoculation for $2 \mathrm{~h}$, most of the ADSCs on the TCP were already attached and extended to the plate. Cells on the mTG/GA, C-mTG/GA, and A-mTG/GA hydrogels showed some pseudopods and were stellate or irregular in shape. Some rounded cells still not attached to the surface of chitosan and alginate hydrogels were present. After inoculation for 1 day, most cells showed spreading activity, and cell proliferation was observed on the surface of C-mTG/GA and A-mTG/GA hydrogels. The elongation of ADSCs was also observed on the surface of mTG/GA hydrogel. Nevertheless, the cells on the surface of the chitosan and alginate hydrogels remained round in shape. Some of the cells on the surface of these hydrogels were surrounded by a ring shadow, indicating that cells were moving in and out within a relatively small space. These cells were trying to stretch out their pseudo feet. However, because no cell adhesion sites were present, these cells were unable to adhere to the surrounding hydrogel tightly, and hardly any stretching was maintained. Therefore, when these shadows appear, the range of cell activity can be inferred indirectly. The images at day 3 clearly showed the cells reached confluence and covered the surface of C-mTG/GA and A-mTG/GA hydrogels. The cells on the surface of chitosan hydrogel grew inward because of the inadequate strength for cell spreading. A few of the polygonal ADSCs were recorded on the surface of the alginate hydrogel. 
401

402

403

404

405

406

407

408

409

410

411

412

413

414

415

416

417

418

419

420

421

422

423

424

425

426

427

428

429

430

431

432

433

434

435

436

437

438

439

440

441

Figure 3. Cell growth at $2 \mathrm{~h}, 1$ day, and 3 days were observed by using an inverted phase contrast microscope. A1-A3. chitosan hydrogels, B1-B3. alginate hydrogels, C1-C3. mTG/GA hydrogels, D1-D3. C-mTG/GA hydrogels, E1-E3. A-mTG/GA hydrogels, and F1-F3. TCPs. Scale bar $=200 \mu \mathrm{m}$.

\section{Cell viability}

The viability of ADSCs on the hydrogels was determined using live/dead staining assay by imaging live and dead cells under a fluorescent microscope. Cells that lost membrane integrity and were no longer viable were stained red (dead cells), whereas the viable cells were stained green (live cells) (Fig.4). The five hydrogels show good biocompatibility and were suitable for cell 2D culture. Although the proportion of dead cells was small in 2D cultures, cells seeded on chitosan and alginate hydrogel displayed negative growth (10-20 live cells per visual field at 10× magnification) over the 5 days and remained circular in shape. The cells on mTG/GA hydrogel, C-mTG/GA, and A-mTG/GA hydrogels grew in size and clustered together. The numbers of live ADSCs cultured on mTG/GA and A-mTG/GA hydrogels in each visual field were more than 100 cells, and the numbers of dead cells in same visual fields were less than 10 cells. The average quantity of live cells on C-mTG/GA hydrogel was slightly less ( 75 live cells per visual field) than on the other hydrogels. Cell shape progressively assumed prickly or rhombohedral patterns. The cell morphology indicated that the cell development may progress to achieve a 3D shape instead of a flat 2D shape. The ADSCs on the C-mTG/GA hydrogel appeared to stretch out to different directions in a 3D hydrogel space (the circle of Fig. 4D). The ADSCs developed on TCPs showed higher quantity and a spreading shape.

Figure 4. Live/dead cell staining results after 5 days of culture. The cytoplast of live cells emitted green fluorescence when stained with calcein-AM. The nuclei of dead cells emitted red fluorescence when stained with PI. A. chitosan hydrogels, B. alginate hydrogels, C. mTG/GA hydrogels, D. C-mTG/GA hydrogels, E. A-mTG/GA hydrogels, and F. TCPs. Scale bar $=200 \mu \mathrm{m}$.

Live/dead staining of ADSCs embedded in the five hydrogels, shown in Fig. 5, revealed that $>90 \%$ of cells survived the $3 \mathrm{D}$ culture. At day 5 in culture, it was evident that GAcontaining hydrogels promoted spreading of embedded cells and resulted in more surviving cells compared to chitosan and alginate hydrogels. According to the images recorded by the inverted fluorescent microscope, ADSCs remained a rounded morphology in chitosan and alginate hydrogels after 5 days of culture. While in mTG/GA, C-mTG/GA, and A-mTG/GA hydrogels, the cells assumed barbed-like morphology with numerous cell protrusions stretching out in different directions, which represented the three hydrogels supporting the cell survival and adhesion. 
442

443

444

445

446

447

448

449

450

451

452

453

454

455

456

457

458

459

460

461

462

463

464

465

466

467

468

469

470

471

472

473

474

475

476

477

478

479

480

481

482

Figure 5. Observing cell viability in $3 \mathrm{D}$ cultures at 5 days. A1-A3. chitosan hydrogels, B1B3. alginate hydrogels, C1-C3. mTG/GA hydrogels, D1-D3. C-mTG/GA hydrogels, E1-E3. A$\mathrm{mTG} / \mathrm{GA}$ hydrogels. Scale bar $=200 \mu \mathrm{m}$.

\section{MTT assay results}

Significant difference in cell growth behavior was observed from day 0 to day 6 (Fig. 6). Although the same number of cells were seeded on day 0 , the number of cells cultured on each hydrogel was less than that of the TCP control group at different time intervals, and the difference was statistically significant $(\mathrm{P}<0.05)$. There was an adaptation period, during which the cells grew on the materials. Some cells were detached from hydrogels. As a result, the number of cells on the hydrogels was certainly less than that of the control group. However, if the duration of measurement was longer, then the number of cells on the materials may increase. In our previous experiments (Yang et al. 2016), the number of cells growing on the materials could exceed the number of cells on TCPs with increasing measurement time. The purpose of this study was to determine the effects of different materials on cell compatibility and proliferation, but not to compare the difference of cell growth behavior between hydrogels and the control group. Therefore, long-term MTT assay ( $>2$ weeks) was not performed. Compared with ADSCs on alginate and chitosan hydrogels, those on mTG/GA and the two composite hydrogels showed more cells and a faster proliferation rate. A decrease in cell proliferation was observed from samples on the chitosan and alginate hydrogels on day 4 , and such a decrease may have been due to the poor adhesion of the cells on these two materials. Some cells were lost when the culture medium was changed routinely on day 3 .

Figure 6. The proliferation of the ADSC cultured on the hydrogels and TCPs after 0, 2, 4, and 6 days of culture, as determined by MTT assay.

\section{Cytoskeleton staining}

Cytoskeleton is a network system of protein fibers in eukaryotic cells. In a narrow sense, the cytoskeleton is composed of microtubules, microfilaments, and intermediate fibers.

Microfilaments are spiral fibers composed of filamentous actin (F-actin). When the adherent cells spread out and became larger on the culture surface, the expression of actin increased, which led to the formation of the actin network. FITC-phalloidin is a kind of microfilament depolymerization inhibitor that has a strong affinity with actin filaments and only binds to Factin. Therefore, only the F-actin of the ADSCs seeded on the hydrogels with excellent properties in cell adhesion and growth can be examined with FITC-phalloidin.

Fig. 7 shows the spreading and morphology of ADSCs grown on hydrogels and TCPs. ADSCs cultured on chitosan hydrogel for 5 days were still round and had no obvious cytoskeletal structure. The chitosan hydrogel showed poor properties for cell adhesion and growth, and the myofilament structure did not form in the cells. Few ADSCs on alginate hydrogel were polygonal, and few actin fibers were observed on the edge of the cells. ADSCs on 
$483 \mathrm{C}-\mathrm{mTG} / \mathrm{GA}$ hydrogel showed a radial arrangement of microfilament cytoskeleton. The staining 484 images of ADSCs on A-mTG/GA and mTG/GA hydrogels were similar to those of the cells on 485 TCPs. Most cells spread on the surface of the material, and the cytoskeleton network was orderly 486 arranged.

487

488

489

490

491

492

493

494

495

496

497

498

499

500

501

502

503

504

505

506

507

508

509

510

511

512

513

514

515

516

517

518

519

520

521

522

Figure 7. Cytoskeleton staining. A. chitosan hydrogels, B. alginate hydrogels, C. mTG/GA hydrogels, D. C-mTG/GA hydrogels, E. A-mTG/GA hydrogels, and F. TCP. Scale bar $=100 \mu \mathrm{m}$.

\section{Discussion}

To better mimic the physiological, biochemical, and physical cues of native tissues, the hybrid materials have extensively been explored. At a minimum, the preferred biomaterial for tissue engineering needs to meet the following essential criteria (Yue et al. 2020; Zhang et al. 2019): 1) biodegradability, 2) proper elastic modulus, and 3) good biocompatibility.

In the field of regenerative medicine, the scaffold material usually needs to be biodegradable (Wang et al. 2019). However, some exceptions exist, such as bone, articular cartilage, or cornea tissue engineering, which require stability of the implanted material (Rastogi \& Kandasubramanian 2019). The blending of polymers may affect the degradation behavior. Therefore, degradation test of the scaffolds was conducted in vitro. Under the action of collagenase, the three hydrogels of mTG/GA, C-mTG/GA, and A-mTG/GA showed similar enzymatic degradation rates. Upon addition of trypsin, both $\mathrm{mTG} / \mathrm{GA}$ and C-mTG/GA completely degraded in a short time. These results indicated that enzymatic cross-linking can provide stability of the scaffold but does not hinder the degradation of protein components. However, for A-mTG/GA hydrogels, the speed of enzymatic degradation by trypsin is slower than that of mTG/GA and C-mTG/GA hydrogels, which may be due to the fact that sodium alginate, as a natural anionic polymer, prevents the trypsin activity from entering GA through electrostatic action ( $\mathrm{Lv}$ et al. 2014). Ruvinov et al. also observed that alginate-sulfate hydrogel protected the protein from the hydrolysis of trypsin (Ruvinov et al. 2010). GA and chitosan are biodegradable, whereas alginate shows high stability in vivo (Bedian et al. 2017). In our work, chitosan and alginate hydrogels were more stable to degradation of the two proteases, because the main components of chitosan and alginate gels are polysaccharides. However, alginate hydrogel lost almost half of its mass under the action of trypsin after $12 \mathrm{~h}$. This phenomenon might be related to the addition of $0.01 \%$ EDTA to trypsin. Dimerization of alginate chains is induced by calcium, and as a result, gel networks are formed. Depending on the amount of calcium present in the system, these inter-chain associations can be either temporary or permanent (George \& Abraham 2006). EDTA can chelate $\mathrm{Ca}^{2+}$ (Hafer et al. 2020); the content of calcium in the A-mTG/GA system is reduced, resulting in a thixotropic solution with high viscosity (George \& Abraham 2006), thereby finally showing the decline of solid mass.

The mechanical property of hydrogel governs final tissue engineering usage, e.g. less stiffness and softer hydrogel can be used to soft tissues of the brain, and high stiffness and harder 
523 hydrogel may be effective for hard tissues of bones, thereby prompting us to characterize the 524 mechanical properties of the five types of hydrogels in this study. Our results showed that the

525

526

527

528

529

530

531

532

533

534

535

536

537

538

539

540

541

542

543

544

545

546

547

548

549

550

551

552

553

554

555

556

557

558

559

560

561

562 mTG/GA, C-mTG/GA, and A-mTG/GA hydrogels had higher elastic moduli than that of chitosan and sodium alginate hydrogel. The addition of polysaccharides particles influenced the elastic modulus, while the effect differs depending on the type of polysaccharides used. After adding chitosan to GA, the structural heterogeneities in the composite's network cause descending of the hydrogel's mechanical property, but after adding sodium alginate to GA, the raising of the elastic modulus indicate the increase of physical crosslinking density (Lewandowska-Łańcucka et al. 2017; Li et al. 2018). The stiffness of substrate also aids in cell functioning, i.e. in growing and proliferating (Caliari \& Burdick 2016). ADSCs grown on GA and on the two kinds of mixed hydrogels showed better adhesion and elongation, whereas ADSCs grown on alginate hydrogel showed relatively later adhesion. ADSCs cultured on chitosan hydrogel cannot adhere and grow due to low elastic modulus. Cytoskeleton staining also confirmed this conclusion. The cell morphology of ADSCs on alginate hydrogel was irregular without an obvious cluster-like branch. ADSCs cultured on chitosan hydrogel almost did not form filamentous actin, and the cell shape remained round.

Hydrogels are water-insoluble networks of crosslinked hydrophilic polymers that exhibit swelling capacity in aqueous environments. The ability of water retention by the material strongly depends on the microstructure (Yan et al. 2005). After mixing chitosan into GA, the mixed hydrogel showed a decrease in swelling rate, which may be attributed to the formation of the tight microstructure of chitosan and GA. The swelling rate of the mixed hydrogels of sodium alginate and GA did not change significantly compared with the mTG/GA hydrogel, indicating that alginate molecules had little effect on the microstructure. Nadezhda et al. also considered that the swelling capacity of the microspheres prepared by alginate and GA was mainly regulated by the content of GA (Lewandowska-Łańcucka et al. 2017). The higher swelling capacity of the hydrogels enhances cell proliferation and cell viability by facilitating transport of nutrients into the hydrogels (Annabi et al. 2011; Gu et al. 2020). That corresponds well with our findings.

When the scaffold is implanted into the body, material biocompatibility becomes a key issue. The scaffold material must not induce adverse reactions, sensitization, carcinogenicity, and irritation in cells, tissues, and systems of humans. The material is supposed to degrade itself. The degradation products need to be non-toxic and can be absorbed or metabolized by the human body. Therefore, whether biomaterials can be successfully applied in tissue engineering depends on the biocompatibility of materials and the toxicity of degradation products (Catalano et al. 2013). The biocompatibilities of chitosan, sodium alginate, and GA have been confirmed (Chatelet et al. 2001; Li et al. 1999; Sosnik 2014); however, whether the blending of these three abovementioned polymers affect the biocompatibility of materials needs to be further studied. We found that the composite hydrogel had no cytotoxic effect on ADSCS according to staining results on live and dead cells. In addition to supporting the survival of ADSCs, growth curves based on MTT assay suggested that ADSCs can proliferate in mTG/GA, C-mTG/GA, and A$\mathrm{mTG} / \mathrm{GA}$ hydrogels. All these results indicated that the two composite hydrogels have good 
563 biocompatibility. The composite gels are obtained by physical mixing of GA and

564 polysaccharides, thus they retain various cell-friendly active sites of GA, such as arginine-

565 glycine-aspartic acid (Lee et al. 2003), which then provides cultured cells with a friendly

566 environment for growth and proliferation.

567

568

\section{Conclusions}

569

570

To mimic the chemical composition of natural tissue, the combination of GA and chitosan

571 or alginate was used to successfully fabricate composite hydrogels in this paper. Hydrogels used

572 for cell culture must exhibit desirable characteristics, such as good swelling capacity, proper mechanical property, and biocompatibility. In this study, the physical properties of five

573 hydrogels were assessed. The composite hydrogels showed different mechanical properties and

574 swelling capacities that depended on different polysaccharide added. Most importantly, this

575 study showed that mTG/GA, C-mTG/GA, and A-mTG/GA hydrogels have excellent

576 biocompatibility and can support ADSC survival, adhesion, and proliferation. Therefore, we

577 believe the biomimetic composite hydrogels of GA and polysaccharides could be suggested as

578 promising materials to cell carriers in tissue engineering.

579

580

581

\section{Acknowledgements}

582

583

584

This work was financially supported by The National Natural Science Foundation of China (61571314) and the Science and Technology Department of Sichuan Province, China

585

586

587

588

589

590

591

592

593

594

595

596

597

598

599

600

601

602

603

604

\section{References}

Afewerki S, Sheikhi A, Kannan S, Ahadian S, and Khademhosseini A. 2019. Gelatinpolysaccharide composite scaffolds for 3D cell culture and tissue engineering: Towards natural therapeutics. Bioeng Trans/ Med 4:96-115. 10.1002/btm2.10124

Ahadian S, Sadeghian RB, Salehi S, Ostrovidov S, Bae H, Ramalingam M, and Khademhosseini A. 2015. Bioconjugated Hydrogels for Tissue Engineering and Regenerative Medicine. Bioconjug Chem 26:1984-2001. 10.1021/acs.bioconjchem.5b00360

Annabi N, Fathi A, Mithieux SM, Martens P, Weiss AS, and Dehghani F. 2011. The effect of elastin on chondrocyte adhesion and proliferation on poly ( $\varepsilon$-caprolactone)/elastin composites. Biomaterials 32:1517-1525. 10.1016/j.biomaterials.2010.10.024

Bedian L, Villalba-Rodríguez AM, Hernández-Vargas G, Parra-Saldivar R, and lqbal HM. 2017. Bio-based materials with novel characteristics for tissue engineering applications - A review. Int J Biol Macromol 98:837-846. 10.1016/j.ijbiomac.2017.02.048

Caliari SR, and Burdick JA. 2016. A practical guide to hydrogels for cell culture. Nat Methods 13:405-414. 10.1038/nmeth.3839 
605

606

607

608

609

610

611

612

613

614

615

616

617

618

619

620

621

622

623

624

625

626

627

628

629

630

631

632

633

634

635

636

637

638

639

640

641

642

643

644

645

646

647

648

649

650

651

652

653

654

Catalano E, Cochis A, Varoni E, Rimondini L, and Azzimonti B. 2013. Tissue-engineered skin substitutes: an overview. J Artif Organs 16:397-403. 10.1007/s10047-013-0734-0

Cattelan G, Guerrero Gerbolés A, Foresti R, Pramstaller PP, Rossini A, Miragoli M, and Caffarra Malvezzi C. 2020. Alginate Formulations: Current Developments in the Race for Hydrogel-Based Cardiac Regeneration. Front Bioeng Biotechnol 8:414. 10.3389/fbioe.2020.00414

Chatelet C, Damour O, and Domard A. 2001. Influence of the degree of acetylation on some biological properties of chitosan films. Biomaterials 22:261-268. 10.1016/s01429612(00)00183-6

Chenite A, Chaput C, Wang D, Combes C, Buschmann MD, Hoemann CD, Leroux JC, Atkinson BL, Binette F, and Selmani A. 2000. Novel injectable neutral solutions of chitosan form biodegradable gels in situ. Biomaterials 21:2155-2161. 10.1016/s0142-9612(00)00116-2

da Silva MA, Bode F, Drake AF, Goldoni S, Stevens MM, and Dreiss CA. 2014. Enzymatically cross-linked gelatin/chitosan hydrogels: tuning gel properties and cellular response. Macromol Biosci 14:817-830. 10.1002/mabi.201300472

Derkach SR, Kuchina YA, Kolotova DS, and Voron'ko NG. 2020. Polyelectrolyte Polysaccharide-Gelatin Complexes: Rheology and Structure. Polymers (Basel) 12. 10.3390/polym12020266

Fatima SW, and Khare SK. 2018. Current insight and futuristic vistas of microbial transglutaminase in nutraceutical industry. Microbiol Res 215:7-14. 10.1016/j.micres.2018.06.001

George M, and Abraham TE. 2006. Polyionic hydrocolloids for the intestinal delivery of protein drugs: alginate and chitosan--a review. J Control Release 114:1-14. 10.1016/j.jconrel.2006.04.017

Gu L, Li T, Song X, Yang X, Li S, Chen L, Liu P, Gong X, Chen C, and Sun L. 2020. Preparation and characterization of methacrylated gelatin/bacterial cellulose composite hydrogels for cartilage tissue engineering. Regen Biomater 7:195-202. 10.1093/rb/rbz050

Hafer E, Holzgrabe U, Kraus K, Adams K, Hook JM, and Diehl B. 2020. Qualitative and quantitative (1) H NMR spectroscopy for determination of divalent metal cation concentration in model salt solutions, food supplements, and pharmaceutical products by using EDTA as chelating agent. Magn Reson Chem 58:653-665. 10.1002/mrc.5009

Hernández-González AC, Téllez-Jurado L, and Rodríguez-Lorenzo LM. 2020. Alginate hydrogels for bone tissue engineering, from injectables to bioprinting: A review. Carbohydr Polym 229:115514. 10.1016/j.carbpol.2019.115514

Huang H, Zhang X, Hu X, Dai L, Zhu J, Man Z, Chen H, Zhou C, and Ao Y. 2014. Directing chondrogenic differentiation of mesenchymal stem cells with a solid-supported chitosan thermogel for cartilage tissue engineering. Biomed Mater 9:035008. 10.1088/1748$6041 / 9 / 3 / 035008$

Lee KY, and Mooney DJ. 2012. Alginate: properties and biomedical applications. Prog Polym Sci 37:106-126. 10.1016/j.progpolymsci.2011.06.003

Lee SB, Jeon HW, Lee YW, Lee YM, Song KW, Park MH, Nam YS, and Ahn HC. 2003. Bioartificial skin composed of gelatin and (1-->3), (1-->6)-beta-glucan. Biomaterials 24:2503-2511. 10.1016/s0142-9612(03)00003-6

Lewandowska-Łańcucka J, Mystek K, Mignon A, Van Vlierberghe S, Łatkiewicz A, and Nowakowska M. 2017. Alginate- and gelatin-based bioactive photocross-linkable hybrid materials for bone tissue engineering. Carbohydr Polym 157:1714-1722. 10.1016/j.carbpol.2016.11.051

Li M, Liu X, and Liu X. 2009. [Comparison of characteristics between glutaraldehyde- and genipin-crosslinked gelatin microspheres]. Zhongguo Xiu Fu Chong Jian Wai Ke Za Zhi 23:87-91.

Peer) reviewing PDF | (2020:10:53637:2:0:NEW 28 Jan 2021) 
655

656

657

658

659

660

661

662

663

664

665

666

667

668

669

670

671

672

673

674

675

676

677

678

679

680

681

682

683

684

685

686

687

688

689

690

691

692

693

694

695

696

697

698

699

700

701

702

703

704

Li RK, Jia ZQ, Weisel RD, Mickle DA, Choi A, and Yau TM. 1999. Survival and function of bioengineered cardiac grafts. Circulation 100:li63-69. 10.1161/01.cir.100.suppl_2.ii-63

Li S, Dong S, Xu W, Tu S, Yan L, Zhao C, Ding J, and Chen X. 2018. Antibacterial Hydrogels. Adv Sci (Weinh) 5:1700527. 10.1002/advs.201700527

Liu M, Ishida Y, Ebina Y, Sasaki T, and Aida T. 2013. Photolatently modulable hydrogels using unilamellar titania nanosheets as photocatalytic crosslinkers. Nat Commun 4:2029. 10.1038/ncomms3029

Long H, Ma K, Xiao Z, Ren X, and Yang G. 2017. Preparation and characteristics of gelatin sponges crosslinked by microbial transglutaminase. PeerJ 5:e3665. 10.7717/peerj.3665

Lv Y, Zhang J, Song Y, Wang B, Wang S, Zhao S, Lv G, and Ma X. 2014. Natural anionic polymer acts as highly efficient trypsin inhibitor based on an electrostatic interaction mechanism. Macromol Rapid Commun 35:1606-1610. 10.1002/marc.201400267

Majidi SS, Slemming-Adamsen P, Hanif M, Zhang Z, Wang Z, and Chen M. 2018. Wet electrospun alginate/gelatin hydrogel nanofibers for 3D cell culture. Int $\mathrm{J}$ Biol Macromol 118:1648-1654. 10.1016/j.ijbiomac.2018.07.005

Mazzeo MS, Chai T, Daviran M, and Schultz KM. 2019. Characterization of the Kinetics and Mechanism of Degradation of Human Mesenchymal Stem Cell-Laden Poly(ethylene glycol) Hydrogels. ACS Appl Bio Mater 2:81-92. 10.1021/acsabm.8b00390

Miranda SC, Silva GA, Hell RC, Martins MD, Alves JB, and Goes AM. 2011. Three-dimensional culture of rat BMMSCs in a porous chitosan-gelatin scaffold: A promising association for bone tissue engineering in oral reconstruction. Arch Oral Biol 56:1-15.

10.1016/j.archoralbio.2010.08.018

Möller L, Krause A, Dahlmann J, Gruh I, Kirschning A, and Dräger G. 2011. Preparation and evaluation of hydrogel-composites from methacrylated hyaluronic acid, alginate, and gelatin for tissue engineering. Int J Artif Organs 34:93-102. 10.5301/ijao.2011.6397

Pilipenko N, Gonçalves OH, Bona E, Fernandes IP, Pinto JA, Sorita GD, Leimann FV, and Barreiro MF. 2019. Tailoring swelling of alginate-gelatin hydrogel microspheres by crosslinking with calcium chloride combined with transglutaminase. Carbohydr Polym 223:115035. 10.1016/j.carbpol.2019.115035

Qiu, Xia, Jing, Deng, Xiao, Ming, Xing, Chang, Qing, and Yuan. 2010. Biocompatibility of a chitosan-based injectable thermosensitive hydrogel and its effects on dog periodontal tissue regeneration. Global Chinese Stomatological Congress and 2010 China International stomatological Congress.

Rastogi P, and Kandasubramanian B. 2019. Review of alginate-based hydrogel bioprinting for application in tissue engineering. Biofabrication 11:042001. 10.1088/1758-5090/ab331e

Rosellini E, Cristallini C, Barbani N, Vozzi G, and Giusti P. 2009. Preparation and characterization of alginate/gelatin blend films for cardiac tissue engineering. $J$ Biomed Mater Res A 91:447-453. 10.1002/jbm.a.32216

Rosellini E, Lazzeri L, Maltinti S, Vanni F, Barbani N, and Cascone MG. 2019. Development and characterization of a suturable biomimetic patch for cardiac applications. J Mater Sci Mater Med 30:126. 10.1007/s10856-019-6327-6

Rosellini E, Zhang YS, Migliori B, Barbani N, Lazzeri L, Shin SR, Dokmeci MR, and Cascone MG. 2018. Protein/polysaccharide-based scaffolds mimicking native extracellular matrix for cardiac tissue engineering applications. J Biomed Mater Res A 106:769-781. 10.1002/jbm.a.36272

Ruvinov E, Leor J, and Cohen S. 2010. The effects of controlled HGF delivery from an affinitybinding alginate biomaterial on angiogenesis and blood perfusion in a hindlimb ischemia model. Biomaterials 31:4573-4582. 10.1016/j.biomaterials.2010.02.026

Saberianpour S, Karimi A, Nemati S, Amini H, Alizadeh Sardroud H, Khaksar M, Mamipour M, Nouri M, and Rahbarghazi R. 2019. Encapsulation of rat cardiomyoblasts with alginate-

Peer) reviewing PDF | (2020:10:53637:2:0:NEW 28 Jan 2021) 
705

706

707

708

709

710

711

712

713

714

715

716

717

718

719

720

721

722

723

724

725

726

727

728

729

730

731

732

733

734

735

736

737

738

739

740

741

742

743

744

745

746

747

748

749

750

751

gelatin microspheres preserves stemness feature in vitro. Biomed Pharmacother 109:402-407. 10.1016/j.biopha.2018.10.119

Sacco P, Furlani F, De Marzo G, Marsich E, Paoletti S, and Donati I. 2018. Concepts for Developing Physical Gels of Chitosan and of Chitosan Derivatives. Gels 4. 10.3390/gels4030067

Schwach V, and Passier R. 2019. Native cardiac environment and its impact on engineering cardiac tissue. Biomater Sci 7:3566-3580. 10.1039/c8bm01348a

Song K, Qiao M, Liu T, Jiang B, Macedo HM, Ma X, and Cui Z. 2010. Preparation, fabrication and biocompatibility of novel injectable temperature-sensitive chitosan/glycerophosphate/collagen hydrogels. J Mater Sci Mater Med 21:2835-2842. 10.1007/s10856-010-4131-4

Sosnik A. 2014. Alginate Particles as Platform for Drug Delivery by the Oral Route: State-of-theArt. ISRN Pharm 2014:926157. 10.1155/2014/926157

Sun J, and Tan H. 2013. Alginate-Based Biomaterials for Regenerative Medicine Applications. Materials (Basel) 6:1285-1309. 10.3390/ma6041285

Supper S, Anton N, Seidel N, Riemenschnitter M, Curdy C, and Vandamme T. 2014. Thermosensitive chitosan/glycerophosphate-based hydrogel and its derivatives in pharmaceutical and biomedical applications. Expert Opin Drug Deliv 11:249-267. 10.1517/17425247.2014.867326

Suzuki E, Fujita D, Takahashi M, Oba S, and Nishimatsu H. 2015. Adipose tissue-derived stem cells as a therapeutic tool for cardiovascular disease. World J Cardiol 7:454-465. 10.4330/wjc.v7.i8.454

Tønnesen HH, and Karlsen J. 2002. Alginate in drug delivery systems. Drug Dev Ind Pharm 28:621-630. 10.1081/ddc-120003853

Wang Y, Jiang Z, Xu W, Yang Y, Zhuang X, Ding J, and Chen X. 2019. Chiral Polypeptide Thermogels Induce Controlled Inflammatory Response as Potential Immunoadjuvants. ACS Appl Mater Interfaces 11:8725-8730. 10.1021/acsami.9b01872

Wang Y, Li B, Zhou Y, and Jia D. 2009. In Situ Mineralization of Magnetite Nanoparticles in Chitosan Hydrogel. Nanoscale Res Lett 4:1041-1046. 10.1007/s11671-009-9355-1

Xu T, Baicu C, Aho M, Zile M, and Boland T. 2009. Fabrication and characterization of bioengineered cardiac pseudo tissues. Biofabrication 1:035001. 10.1088/1758$5082 / 1 / 3 / 035001$

Yan Y, Wang X, Xiong Z, Liu H, Liu F, Lin F, Wu R, Zhang R, and Lu Q. 2005. Direct Construction of a Three-dimensional Structure with Cells and Hydrogel. 20:259-269. 10.1177/0883911505053658

Yang G, Xiao Z, Ren X, Long H, Qian H, Ma K, and Guo Y. 2016. Enzymatically crosslinked gelatin hydrogel promotes the proliferation of adipose tissue-derived stromal cells. PeerJ 4:e2497. 10.7717/peerj.2497

Yue S, He H, Li B, and Hou T. 2020. Hydrogel as a Biomaterial for Bone Tissue Engineering: A Review. Nanomaterials (Basel) 10. 10.3390/nano10081511

Zhang Y, Yu J, Ren K, Zuo J, Ding J, and Chen X. 2019. Thermosensitive Hydrogels as Scaffolds for Cartilage Tissue Engineering. Biomacromolecules 20:1478-1492. 10.1021/acs.biomac.9b00043

Zhou HY, Jiang LJ, Cao PP, Li JB, and Chen XG. 2015. Glycerophosphate-based chitosan thermosensitive hydrogels and their biomedical applications. Carbohydr Polym 117:524536. 10.1016/j.carbpol.2014.09.094

Peer) reviewing PDF | (2020:10:53637:2:0:NEW 28 Jan 2021) 


\section{Table 1 (on next page)}

Gelation time, swelling rate and compression modulus of the five tested hydrogels.

$*^{* \wedge} \mathrm{P}<0.05$ 


\begin{tabular}{|cccccc|}
\hline Samples & $\begin{array}{c}\text { Chitosan } \\
\text { hydrogels }\end{array}$ & $\begin{array}{c}\text { Alginate } \\
\text { hydrogels }\end{array}$ & $\begin{array}{c}\text { mTG/GA } \\
\text { hydrogels }\end{array}$ & $\begin{array}{c}\text { C-mTG/GA } \\
\text { hydrogels }\end{array}$ & $\begin{array}{c}\text { A-mTG/GA } \\
\text { hydrogels }\end{array}$ \\
$\begin{array}{c}\text { Gelation time } \\
\text { (min) }\end{array}$ & $<10$ & $<10$ & $\sim 30$ & $<20$ & $<20$ \\
$\begin{array}{c}\text { Swelling rate } \\
(\%)\end{array}$ & $1.55 \pm 0.89^{*} \#$ & $4.68 \pm 0.87^{*} \#$ & $21.33 \pm 1.78 \#$ & $14.29 \pm 2.28^{*} \#$ & $20.72 \pm 0.84^{*}$ \\
$\begin{array}{c}\mathbf{( \% )} \\
\text { Compression }\end{array}$ & $3.48 \pm 0.45^{\wedge}$ & $7.06 \pm 1.22^{\wedge}$ & $17.42 \pm 1.34^{\wedge}$ & $14.29 \pm 2.64^{\wedge}$ & $19.79 \pm 1.22^{\wedge}$ \\
\hline
\end{tabular}


Figure 1

Schematic elucidating the preparation and characterization of the five hydrogels.

A. Schematic showing the five hydrogels fabrication process. (1) Preparation of chitosan

hydrogel. (2) Preparation of alginate hydrogel. (3) Preparation of mTG/GA hydrogel. (4)

Preparation of two composite hydrogels. B. Characterization and biological assessments of the five hydrogels. C-G. The appearance of the five tested hydrogels. Scale bar $=1 \mathrm{~cm}$.
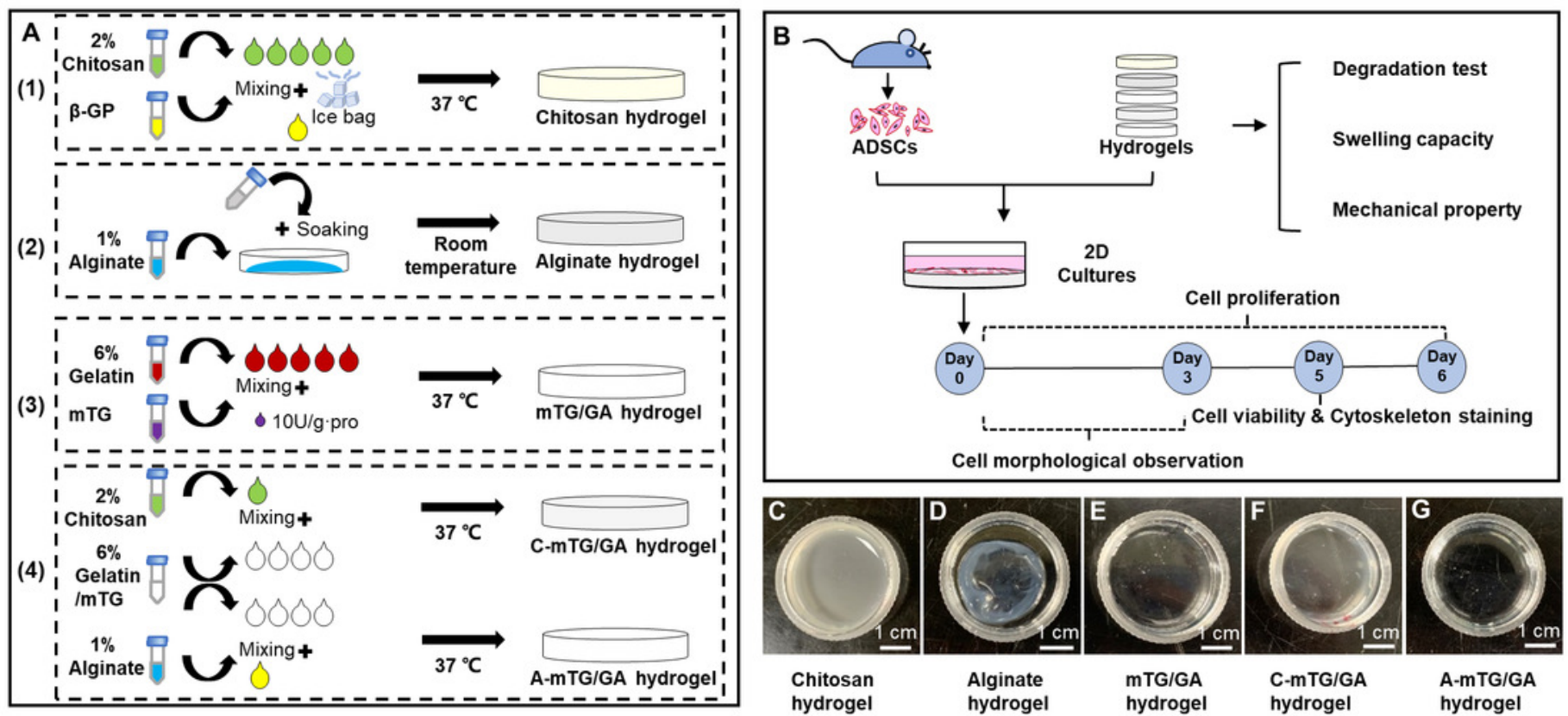
Figure 2

In vitro enzymatic degradation property of the five hydrogels.

A. Schematic showing the five hydrogels fabrication process. (1) Preparation of chitosan hydrogel. (2) Preparation of alginate hydrogel. (3) Preparation of mTG/GA hydrogel. (4) Preparation of two composite hydrogels. B. Characterization and biological assessments of the five hydrogels. C-G. The appearance of the five tested hydrogels. Scale bar $=1 \mathrm{~cm}$.

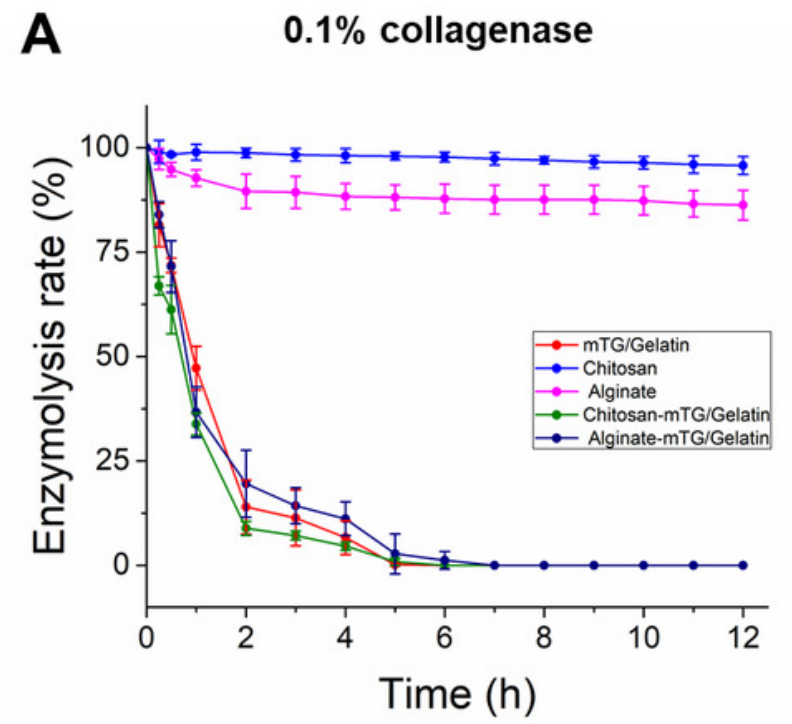

C Hydrolytic degradation

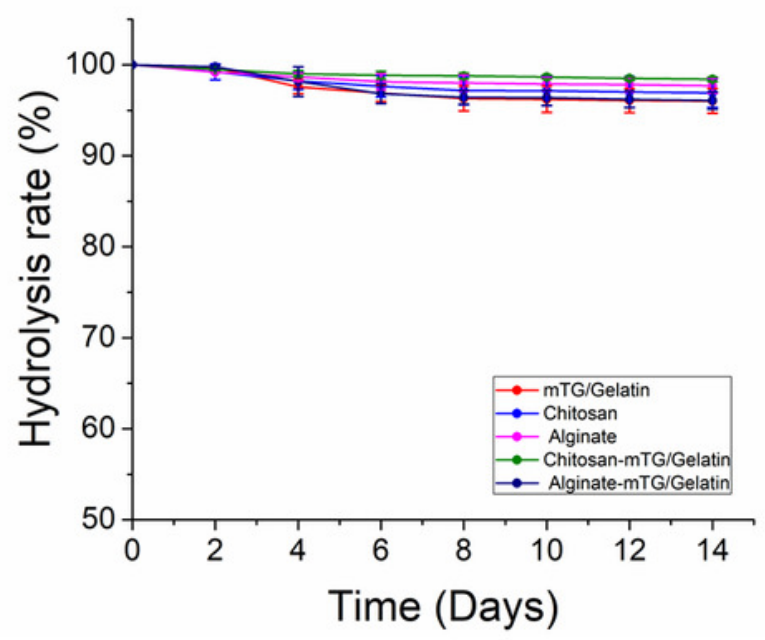

B $\quad 0.25 \%$ trypsin $/ 0.01 \%$ EDTA

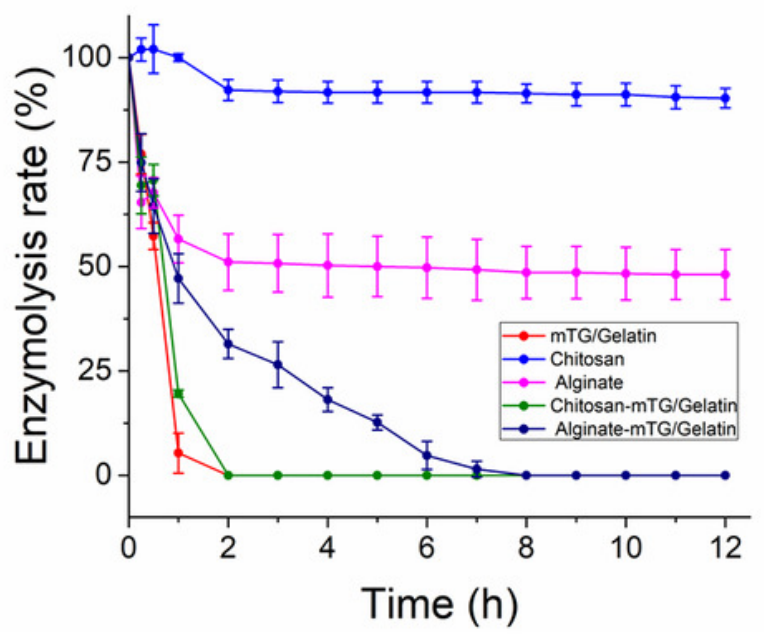

D Cellular degradation

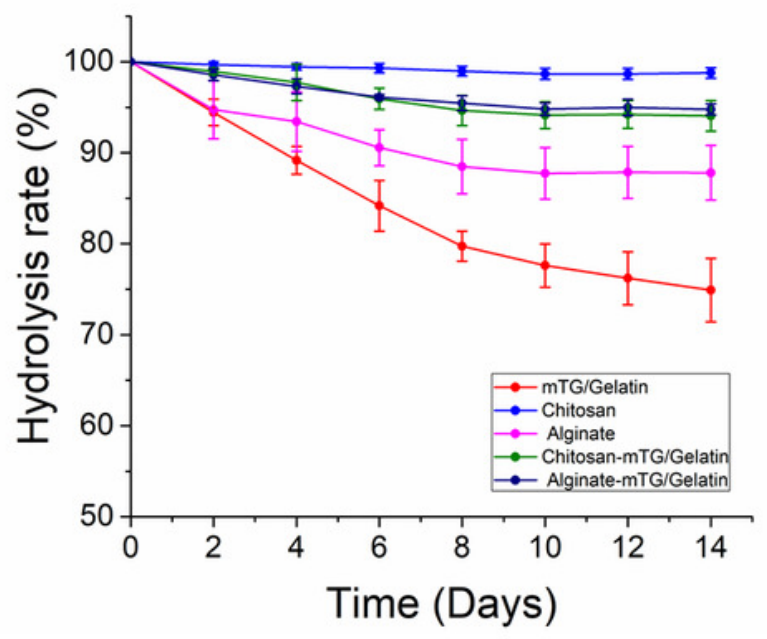




\section{Figure 3}

Cell growth at 2 h, 1 day, and 3 days were observed by using an inverted phase contrast microscope.

A1-A3. chitosan hydrogels, B1-B3. alginate hydrogels, C1-C3. mTG/GA hydrogels, D1-D3. CmTG/GA hydrogels, E1-E3. A-mTG/GA hydrogels, and F1-F3. TCPs. Scale bar $=200 \mu \mathrm{m}$.

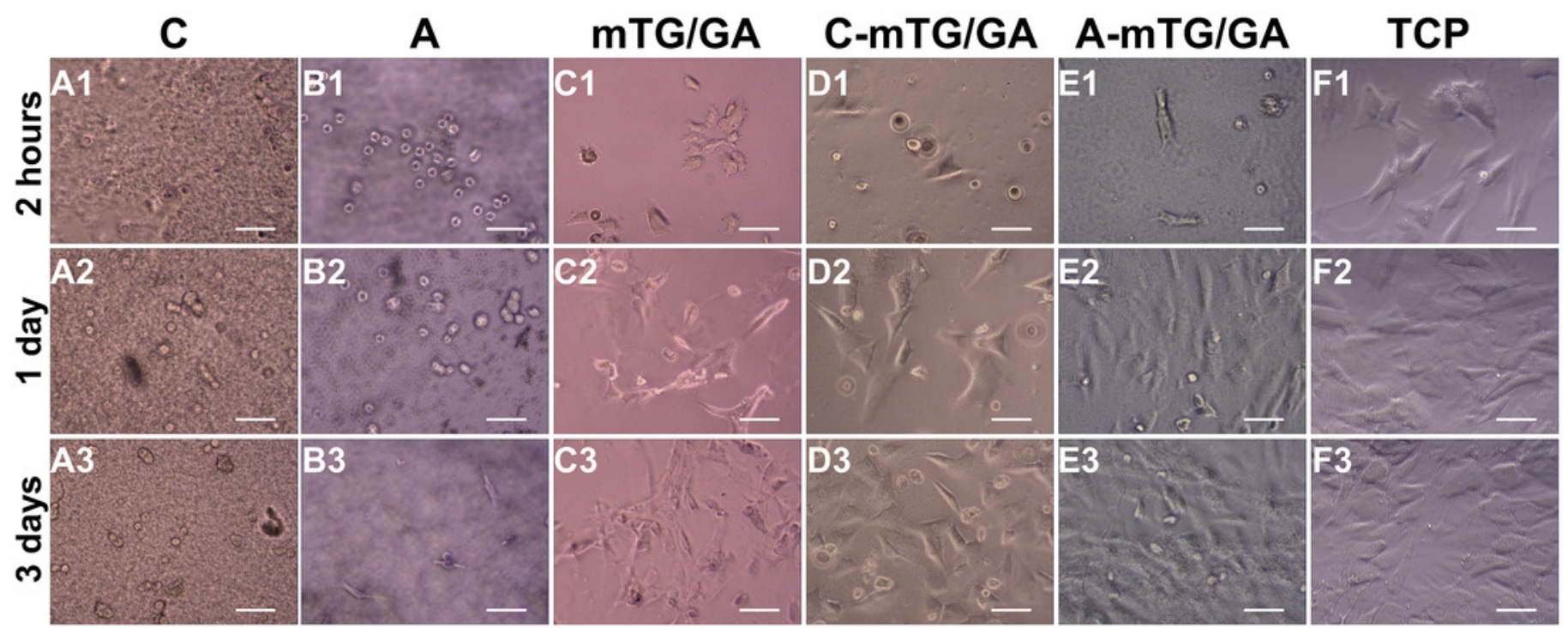




\section{Figure 4}

Live/dead cell staining results after 5 days of culture.

The cytoplast of live cells emitted green fluorescence when stained with calcein-AM. The nuclei of dead cells emitted red fluorescence when stained with PI. A. chitosan hydrogels, B. alginate hydrogels, C. mTG/GA hydrogels, D. C-mTG/GA hydrogels, E. A-mTG/GA hydrogels, and F. TCPs. Scale bar $=200 \mu \mathrm{m}$.
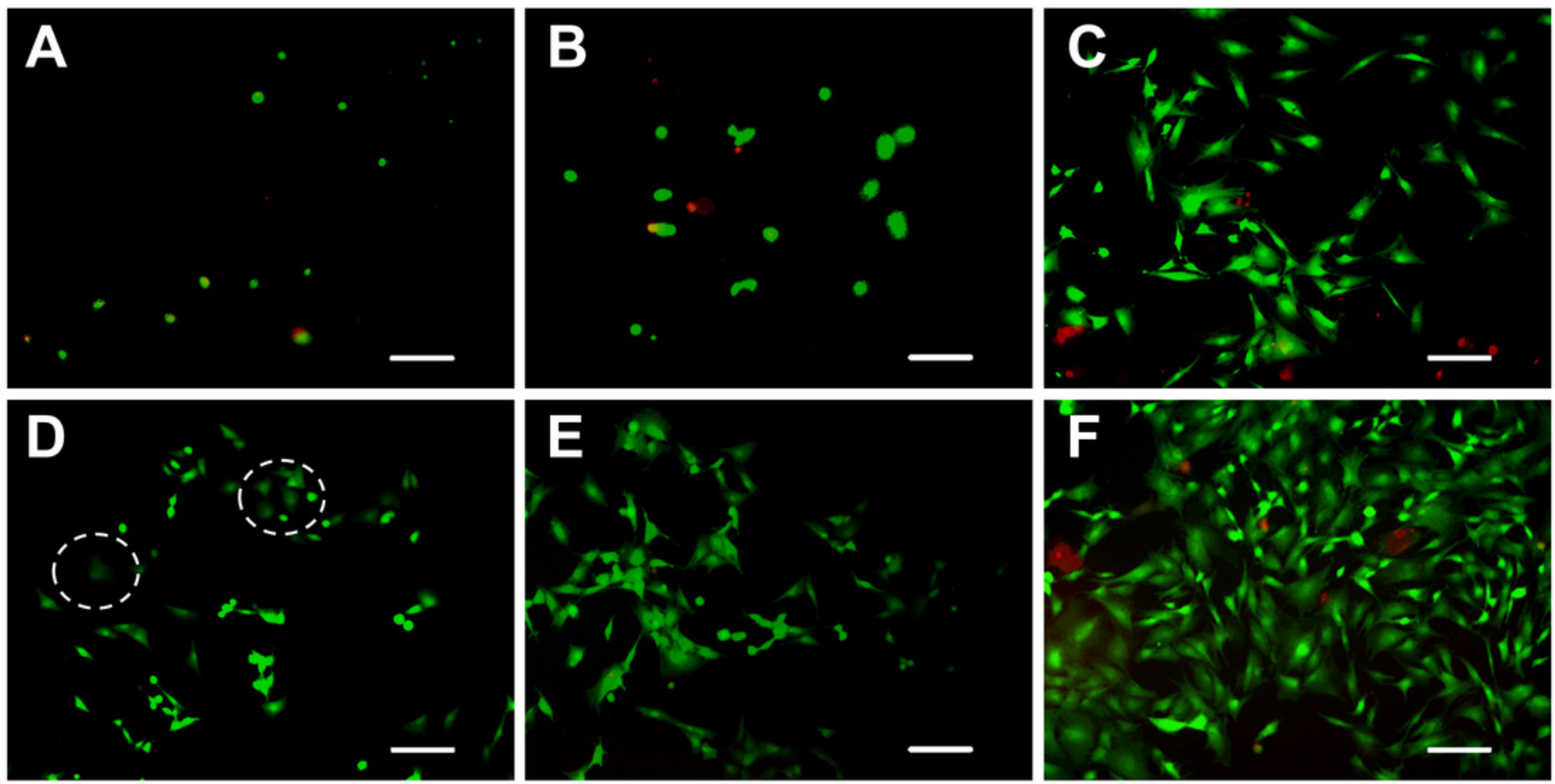
Figure 5

Observing cell viability in 3D cultures at 5 days.

A1-A3. chitosan hydrogels, B1-B3. alginate hydrogels, C1-C3. mTG/GA hydrogels, D1-D3. CmTG/GA hydrogels, E1-E3. A-mTG/GA hydrogels. Scale bar $=200 \mu \mathrm{m}$. 


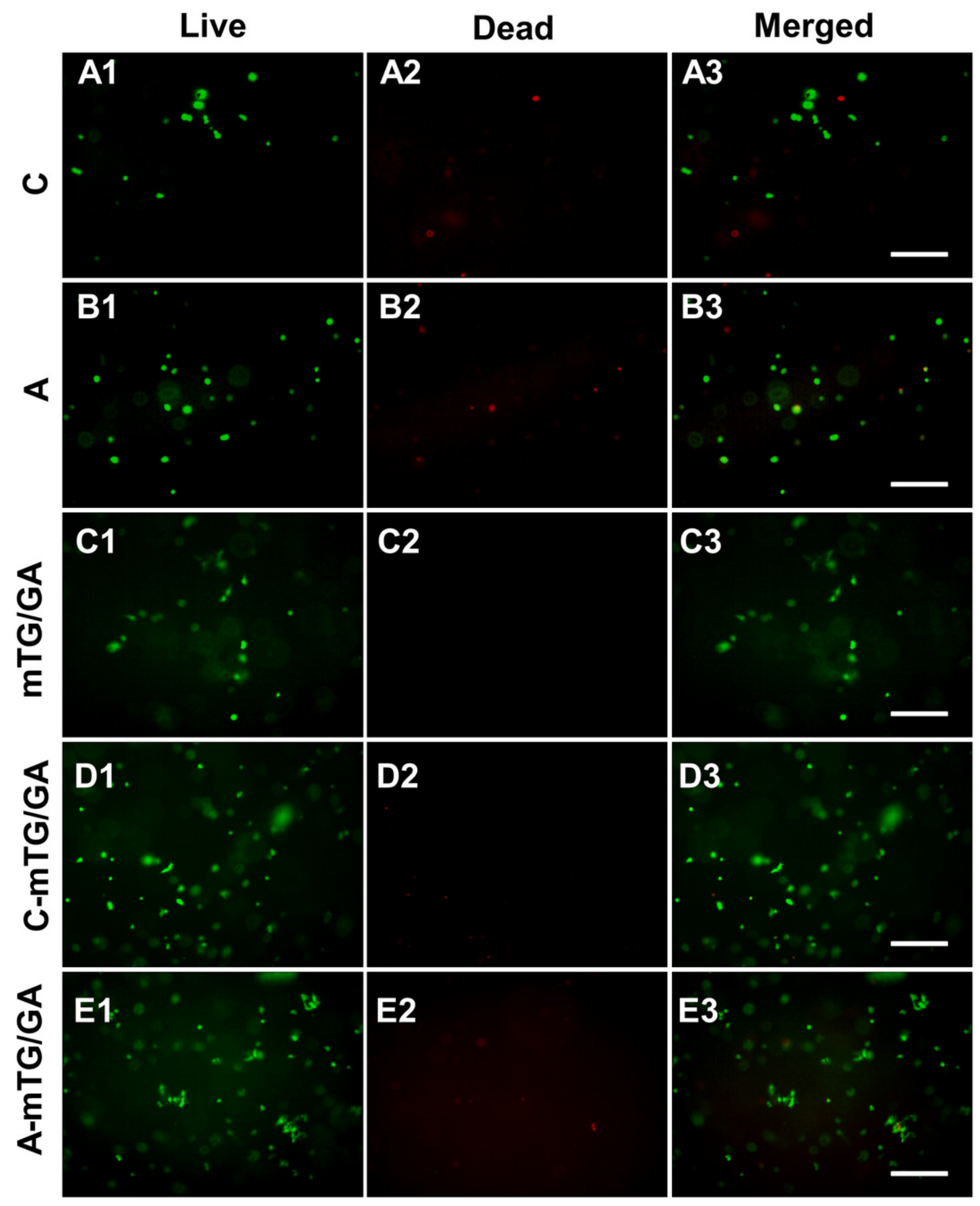


Figure 6

The proliferation of the ADSC cultured on the hydrogels and TCPs after $0,2,4$, and 6 days of culture, as determined by MTT assay.

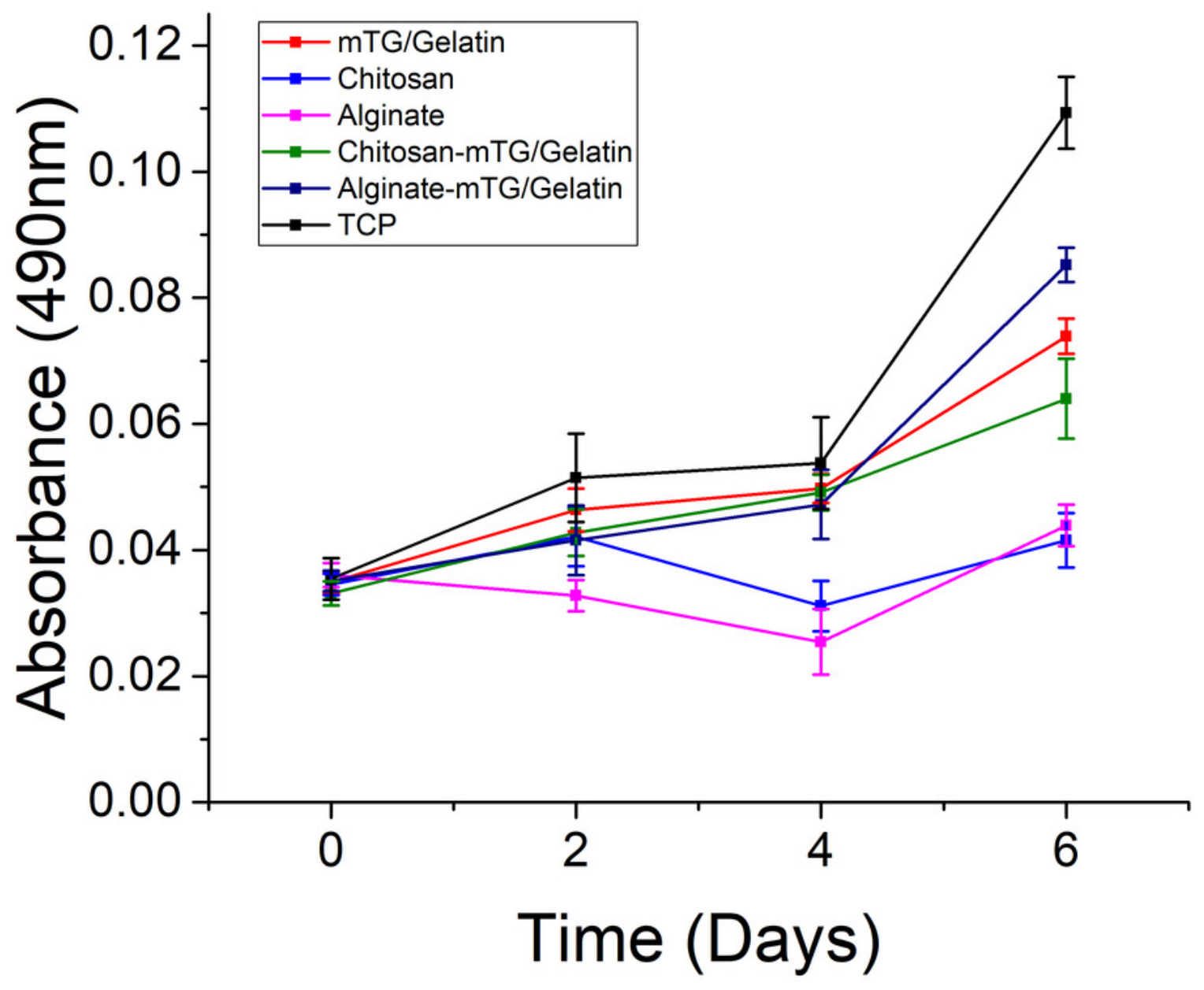




\section{Figure 7}

Cytoskeleton staining.

A. chitosan hydrogels, B. alginate hydrogels, C. mTG/GA hydrogels, D. C-mTG/GA hydrogels,

E. A-mTG/GA hydrogels, and F. TCP. Scale bar $=100 \mu \mathrm{m}$.

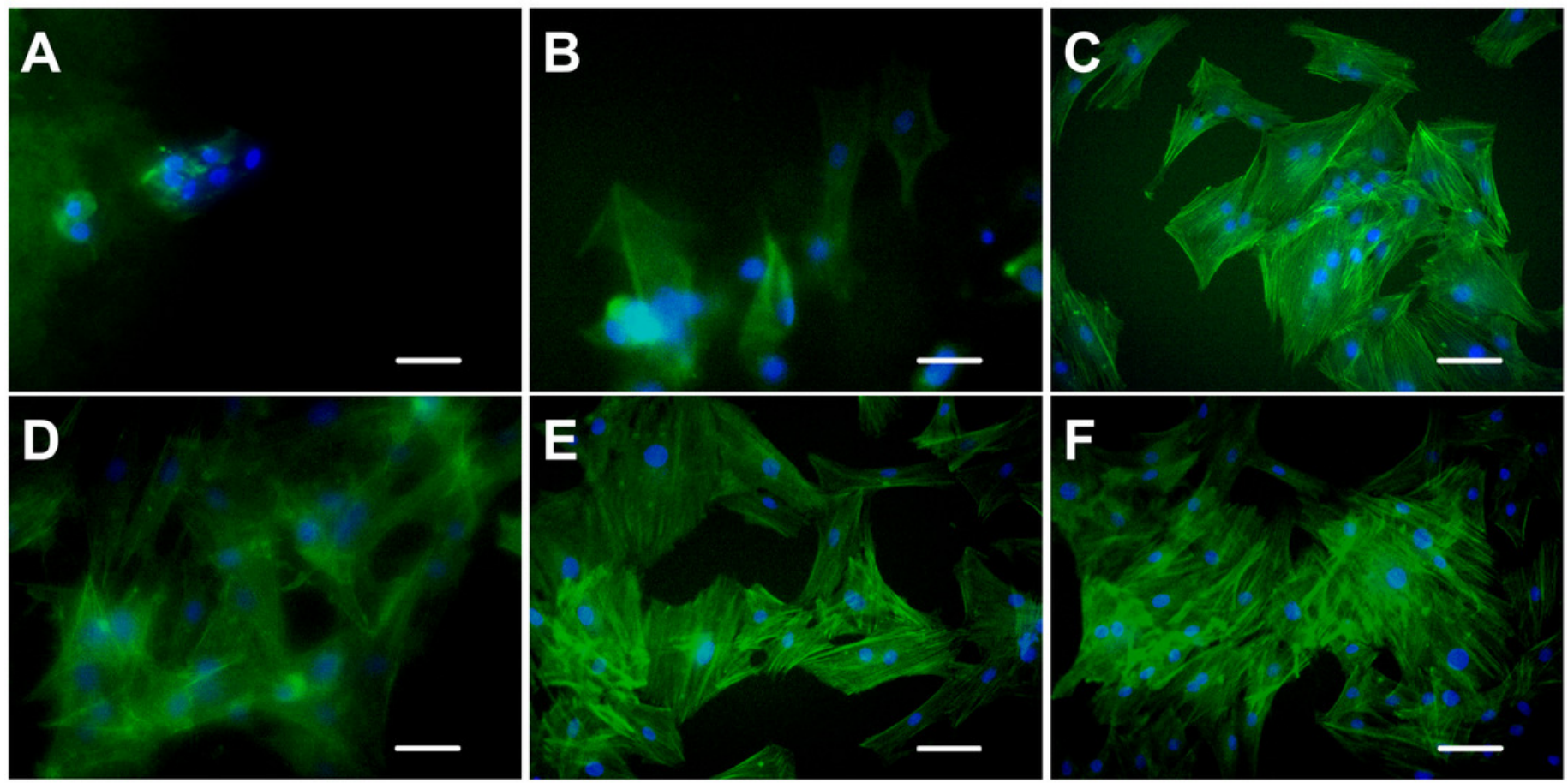

